\title{
A rapid HPLC method for indirect quantification of $\beta$-lactamase activity in milk
}

\author{
Shuang Zhou, Dan Wang, Yunfeng Zhao, ${ }^{1}$ and Yongning $\mathrm{Wu}^{1}$ \\ China National Center for Food Safety Risk Assessment, Key Laboratory of Food Safety Risk Assessment, Ministry of Health, \\ Beijing 100021, P. R. China
}

\begin{abstract}
To circumvent the strictly regulated limits of antibiotics in milk, illegal addition of $\beta$-lactamase to lower the antibiotic levels in milk has been reported recently in China. Herein, we describe a fast, sensitive, and robust HPLC-UV method for the determination of $\beta$-lactamase activity in milk, based on an indirect quantification strategy. The test milk sample was mixed with a known amount of penicillin $\mathrm{G}$, a specific substrate of $\beta$-lactamase. After incubation, an aliquot of the mixture was injected into the HPLC-UV system to quantify the remaining penicillin $\mathrm{G}$ in less than 10 min. Comparative analysis of the amount of penicillin $\mathrm{G}$ before and after incubation was used to indirectly deduce the activity of $\beta$-lactamase in the test sample. This method was successfully applied to milk products with different fat percentages, resulting in a detection limit of $0.6 \mathrm{U} / \mathrm{mL}$. Good recoveries, ranging from 94 to $105 \%$, were obtained from blank milk samples spiked with $\beta$-lactamase at levels of 2 to $50 \mathrm{U} / \mathrm{mL}$, with relative standard deviations $<6 \%$. A good correlation was demonstrated between the HPLC method and the conventional culture-based assay. Using this method, the activity changes in $\beta$-lactamase during milk pasteurization, sterilization, and storage were investigated. The advantages of low-cost, accurate quantification and easily accessible instrumentation make the proposed method an ideal alternative for high-throughput routine analysis in the dairy industry.
\end{abstract}

Key words: $\beta$-lactamase, antibiotics, milk, highperformance liquid chromatography (HPLC)

\section{INTRODUCTION}

Antibiotics, especially penicillin and cephalosporin, are widely used as veterinary medicines in the dairy

\footnotetext{
Received September 11, 2014

Accepted November 22, 2014.

${ }^{1}$ Corresponding authors: zhaoyf@cfsa.net.cn and wuyongning@cfsa. net.cn
}

industry to treat animals with bacterial infections (Ashwin et al., 2005; Stead et al., 2008). However, their improper use easily leads to antibiotic contamination of milk, which may contravene regulatory restrictions. Since the 1980s, $\beta$-lactamase has been added to contaminated milk to degrade antibiotics in order to circumvent regulations and achieve significant economic benefit (Korycka-Dahl et al., 1985). This illegal act is becoming more common in China (Cui et al., 2007; Xu et al., 2010). If consumed by humans, $\beta$-lactamase can lead to antibiotic resistance and thus high susceptibility to infections (Kantiani et al., 2009; Pengov and Kirbis, 2009). Moreover, addition of $\beta$-lactamase enables the presence of antibiotics to be concealed, thereby encouraging the overuse of antibiotics during milk production, storage, and transportation. Most importantly, insufficiently purified $\beta$-lactamase may contain toxic substances that themselves would constitute a public health threat. Hence, regular monitoring and surveillance of $\beta$-lactamase in milk is of great importance.

The $\beta$-lactamases (EC 3.5.2.6) are a well-studied family of enzymes that specifically catalyze the hydrolytic degradation of the 4-member $\beta$-lactam ring in certain types of antibiotics, resulting in their inactivation (Abraham and Chain, 1940). To date, more than 400 different structures of $\beta$-lactamase have been discovered and divided into 4 classes according to the Bush method (Bush and Jacoby, 2010). The structural diversity of $\beta$-lactamases is a challenge to screening techniques used to directly identify the specific AA or nucleic acid sequences of the enzyme: PCR (López-Cerero et al., 2011; Voets et al., 2011), immunoassays (Hujer et al., 2002, 2009), spectrophotometric assays (Gao et al., 2003; Perret, 1954; Xing et al., 2005), isoelectric focusing (Paterson et al., 2001), and mass spectrometry-based methods (Ikryannikova et al., 2008). On the other hand, indirect methods have been successfully developed that measure the activity of $\beta$-lactamase by monitoring the enzymatic reactions with its specific substrate. The most commonly used are culture-based microbial growth inhibition methods (Livermore and Yuan, 1996; Cui et al., 2007; Goyal et 
al., 2008). Such methods are sensitive and reliable, but their laborious and time-consuming operation limits further application in routine analysis. Thus, several simple and convenient screening and sensing techniques have been developed, based on chromogenic substrates (O'Callaghan et al., 1972; Jorgensen et al., 1982), electrogenerated chemiluminescence (Liang et al., 1996), biocompatible hydrogels (Yang et al., 2007, 2008), gold nanoparticles (Liu et al., 2007), and oligonucleotide microarrays (Rubtsova et al., 2010). However, the requirement of special equipment and the lack of signal stability prohibit their widespread use.

More recently, matrix-assisted laser desorption ionization/Fourier transform mass spectrometry (MALDIFTMS; Xu et al., 2010) was introduced for detection of $\beta$-lactamase in milk, resulting in a significant improvement in sensitivity. This approach was aimed at identifying the presence of $\beta$-lactamase but was unable to accurately quantify enzyme activity. Then, a novel thermometric biosensor was created in our laboratory for fast quantification of $\beta$-lactamase in milk with a detection limit of $1.1 \mathrm{U} / \mathrm{mL}$ (Zhou et al., 2013).

Here, we present another method for indirect quantification of $\beta$-lactamase in milk by monitoring the conversion of its specific substrate during enzymatic reactions using an HPLC-UV system. In this assay, a fixed amount of penicillin $G$ was preincubated with the test sample, and the amount of penicillin G remaining after incubation measured by HPLC was used to deduce the enzyme activity of $\beta$-lactamase. The easy accessibility and high automation of the HPLC system greatly facilitates the widespread application of this assay in dairy product control.

\section{MATERIALS AND METHODS}

\section{Materials and Chemicals}

$\beta$-Lactamase standard $(4,460 \mathrm{kU} / \mathrm{mL})$ was purchased from National Institutes for Food and Drug Control (Beijing, China). Penicillin G (potassium salt, 1,500$1,750 \mathrm{U} / \mathrm{mg}$ ) was from Sigma Chemical Co. (St. Louis, MO). Methanol and acetonitrile (HPLC grade) were purchased from Fisher Scientific (Pittsburgh, PA). The deionized water used in this study was collected from a Milli-Q water purification system (Millipore Corp., Bedford, MA), and all other chemicals were of analytical reagent grade or better. The working dilutions for $\beta$-lactamase and penicillin $\mathrm{G}$ were prepared fresh with $0.01 \mathrm{~mol} / \mathrm{L}$ phosphate buffer (potassium phosphate dibasic + potassium phosphate monobasic, $\mathrm{pH}$ 7.0) on the day of use.

\section{HPLC Apparatus and Conditions}

A Waters 2695 HPLC system (Milford, MA) consisting of a binary solvent manager, an auto sampler, a column oven, and a photo-diode array detector was used in this study. Analysis was performed on a Dikma Diamonsil C18 column $(4.6 \times 150 \mathrm{~mm}, 5 \mu \mathrm{m}$; Beijing, China). A constant mobile phase $(60 \%$ water containing $0.02 M$ potassium dihydrogen phosphate, $40 \%$ methanol) was applied at a flow rate of $1.2 \mathrm{~mL} / \mathrm{min}$. The column temperature was kept at $30^{\circ} \mathrm{C}$ and the detector was set at $210 \mathrm{~nm}$. Instrument control and data processing were conducted with Empower 2 software (Waters).

\section{Sample Treatment}

All milk samples were purchased locally, including skim milk, semi-skim milk, whole milk, modified milk, pasteurized milk, and UHT-sterilized milk. A volume of $2 \mathrm{~mL}$ of the milk sample was pipetted into a $15-\mathrm{mL}$ polypropylene centrifuge tube and $20 \mu \mathrm{L}$ of penicillin G $(5 \mathrm{mg} / \mathrm{mL})$ was added to give a final concentration of $50 \mu \mathrm{g} / \mathrm{mL}$. The mixture was thoroughly vortexed and incubated at $25^{\circ} \mathrm{C}$ for $3 \mathrm{~h}$ under mild agitation. Then, $8 \mathrm{~mL}$ of acetonitrile was added to allow sufficient precipitation of proteins. After centrifugation $(2,600 \times$ $\left.g, 30 \mathrm{~min}, 25^{\circ} \mathrm{C}\right)$ and filtration $(0.22 \mu \mathrm{m})$, an aliquot of the resultant solution was injected into the HPLC apparatus to determine the remaining concentration of penicillin $\mathrm{G}$.

\section{Matrix-Matched Standard Calibration}

Quantification of $\beta$-lactamase was performed by matrix-matched standard calibration. Commercial milk products that contained no $\beta$-lactamase were used as blank matrix to prepare calibration solutions. $\beta$-Lactamase standard was added to the blank matrix to obtain a serial concentrations of $0.0,2.0,4.0,10.0$, 16.0, and $20.0 \mathrm{U} / \mathrm{mL}$. Then, the calibration solutions were processed in the same way as the test samples described above.

\section{Method Validation}

Recovery experiments of the HPLC method were conducted in 6 replicates by analysis of spiked milk samples at concentrations of 2.0,6.0,10.0,20.0, and $50.0 \mathrm{U} /$ $\mathrm{mL}$. The method was further validated by comparing with results from the enzyme thermistor sensor method (Zhou et al., 2013) and an established microbiological 
assay, the modified cylinder plate method (Cui et al., 2007). The same spiked milk samples containing 0, 4.0, 10.0, 20.0, and $40.0 \mathrm{U} / \mathrm{mL} \beta$-lactamase were analyzed simultaneously by using the 3 methods, and their results were compared and evaluated.

\section{RESULTS AND DISCUSSION}

\section{Assay Optimization}

The indirect quantification of $\beta$-lactamase activity was conducted by monitoring conversion of its specific substrate, penicillin $\mathrm{G}$, during enzymatic reactions using the HPLC-UV system. Therefore, a reliable HPLC performance for penicillin $\mathrm{G}$ measurement was of importance. The effects of mobile phase, flow rate, and injection volume were optimized to achieve adequate sensitivity, resolution, and speed. The best chromatograms were obtained when using a mobile phase consisting of $40 \%$ methanol and $60 \%$ phosphate buffer (water containing $0.02 M$ potassium dihydrogen phosphate) for penicillin $\mathrm{G}$ separation (0-10 min), followed by a clean wash step with $90 \%$ menthol and $10 \%$ phosphate buffer (10-12 min) at a flow rate of $1.2 \mathrm{~mL} / \mathrm{min}$.

Milk matrix containing multiple components including fats, proteins, casein micelles, and lactose may cause complex background signals or increase the risk of clogging in the HPLC column. Commonly, complicated milk pretreatment protocols are developed to eliminate the matrix influences on milk analysis, which can be very time consuming. In this study, a rapid and simple procedure was created for milk sample treatment. After being incubated with a fixed amount of penicillin $\mathrm{G}$, the milk sample was diluted 5 times with acetonitrile to remove protein. The resulting solution was directly injected for HPLC analysis following centrifugation $\left(2,600 \times g, 5 \mathrm{~min}, 25^{\circ} \mathrm{C}\right)$ and filtration $(0.22 \mu \mathrm{m})$. Figure 1 shows the chromatograms of different types of milk samples (modified milk and milk with different fat percentages) spiked with $50 \mu \mathrm{g} / \mathrm{mL}$ penicillin G. As can be seen, the penicillin $G$ was separated with the milk matrix components under optimized HPLC conditions.

The appropriate amounts of penicillin $\mathrm{G}$ to add to the test samples were also optimized. Spiked milk samples containing $0,2.0,4.0,10.0$, and $20.0 \mathrm{U} / \mathrm{mL} \beta$-lactamase were incubated with $10,20,50$, and $100 \mu \mathrm{g} / \mathrm{mL}$ penicillin $\mathrm{G}$ for $3 \mathrm{~h}$; the degradation curves of penicillin $\mathrm{G}$ are presented in Figure 2. With increasing $\beta$-lactamase activity from 0 to $20.0 \mathrm{U} / \mathrm{mL}$, the degradation of penicillin G increased correspondingly. By comparing the degradation curves of different concentrations of penicillin G, we observed that low concentrations resulted in a steeper incline and, therefore, better sensitivity.
On the other hand, the sharp drop of the curve slope resulted in a narrow linear range. Thus, to strike a balance between sensitivity and linear range, $50 \mu \mathrm{g} / \mathrm{mL}$ penicillin $\mathrm{G}$ was used in further experiments.

\section{Matrix-Matched Calibration of $\beta$-Lactamase}

The matrix-matched calibration solutions spiked with $0,2.0,4.0,10.0,16.0$, and $20.0 \mathrm{U} / \mathrm{mL} \beta$-lactamase were prepared using blank milk matrix that contained no $\beta$-lactamase. In these calibration solutions, penicillin $\mathrm{G}$ standard was pipetted to give a final concentration of $50 \mu \mathrm{g} / \mathrm{mL}$. Each solution was tested by HPLC after $3 \mathrm{~h}$ of incubation, and chromatograms are shown in Figure $3 a$. The $\beta$-lactamase present in calibration solutions catalyzed the conversion of penicillin $\mathrm{G}$ to penicilloic acid during incubation. Therefore, the peak heights corresponding to the remaining penicillin $\mathrm{G}$ declined significantly from 0 to $20 \mathrm{U} / \mathrm{mL}$, whereas the peaks of penicilloic acid increased accordingly. The $0 \mathrm{U} / \mathrm{mL}$ standard solution gave the highest penicillin G signal, which represented the total added amount.

The calibration curve was plotted as peak height versus $\beta$-lactamase activity (Figure $3 \mathrm{~b}$ ). Good linearity between 0 and $20 \mathrm{U} / \mathrm{mL}$ was obtained with a regression coefficient of 0.997 for quantification of $\beta$-lactamase activity. The detection limit was $0.6 \mathrm{U} / \mathrm{mL}$ [signalto-noise ratio $(\mathrm{S} / \mathrm{N})=3$ ] and the quantification limit was $2.0 \mathrm{U} / \mathrm{mL}(\mathrm{S} / \mathrm{N}=10)$, with intra- and interassay coefficients of variation $<6$ and $8 \%$, respectively. Commercial milk products were spiked with known amounts of $\beta$-lactamase and tested to evaluate the recovery and precision (coefficients of variation; \%). A high recovery yield ranging between 94 and 105\% was achieved with coefficients of variation values of $<6 \%$ (Table 1 ).

\section{HPLC Method Validation}

To further validate the described HPLC method, a conventional microbiological assay (Cui et al., 2007) and a newly developed thermometric biosensor method (Zhou et al., 2013) were used for comparison. In the microbiological assay, $\beta$-lactamase activity was defined as a difference in inhibitory zones between test samples and blank controls, and subsequently classified as negative $(<4 \mathrm{U} / \mathrm{mL})$, positive $(4 \sim 20 \mathrm{U} / \mathrm{mL})$, or high $(>20 \mathrm{U} / \mathrm{mL})$. The biosensor method involved a specific enzyme column and an ultrasensitive thermal detector, which could quantify the activity of $\beta$-lactamase in the range of 1.1 to $20 \mathrm{U} / \mathrm{mL}$ with a detection limit of $1.1 \mathrm{U} / \mathrm{mL}$. Milk samples spiked with $0,4.0,10.0$, 20.0 , and $40.0 \mathrm{U} / \mathrm{mL} \beta$-lactamase were measured by the 3 methods, and their results were in good agree- 

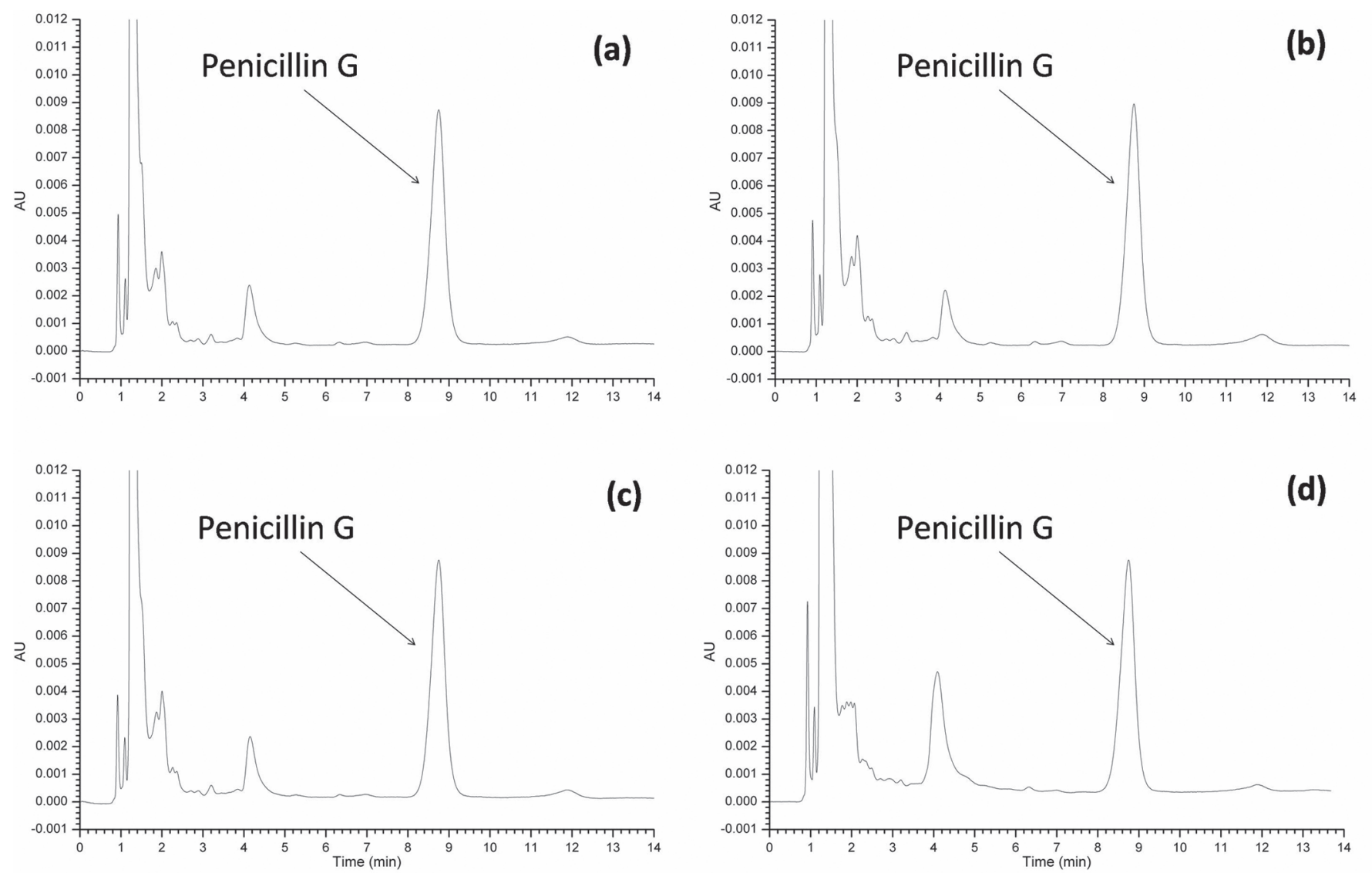

Figure 1. High-performance liquid chromatography-UV chromatograms of (a) skim milk, (b) semi-skim milk, (c) whole milk, and (d) modified milk samples spiked with $50 \mu \mathrm{g} / \mathrm{mL}$ penicillin $\mathrm{G}$.

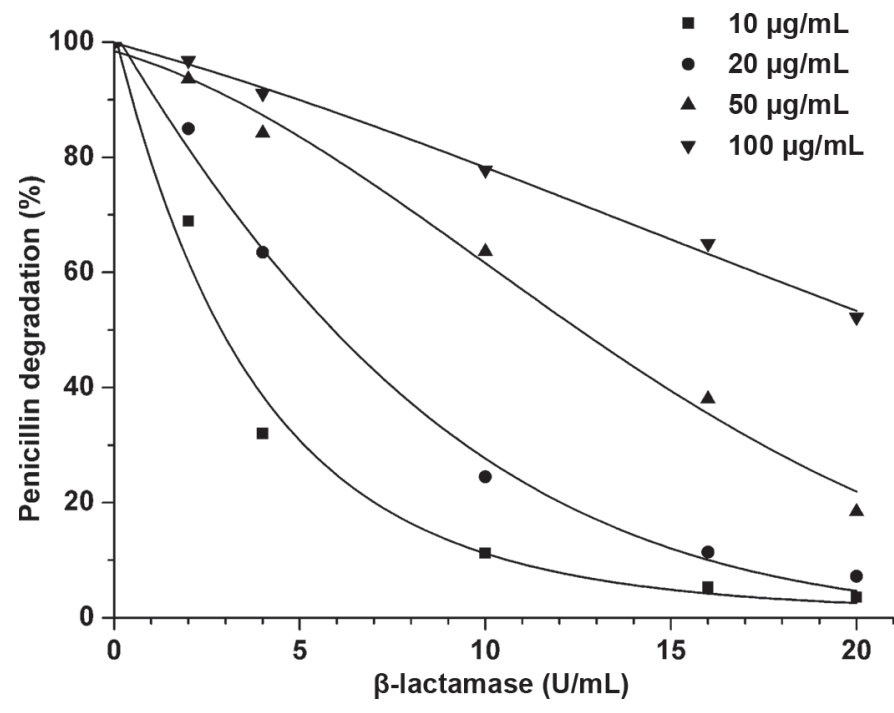

Figure 2. Degradation curves of penicillin $\mathrm{G}$ at different concentrations. The spiked milk samples containing $0,2.0,4.0,10.0,16.0$, and $20.0 \mathrm{U} / \mathrm{mL} \beta$-lactamase were incubated with $10,20,50$, and $100 \mu \mathrm{g} /$ $\mathrm{mL}$ penicillin $\mathrm{G}$ for $3 \mathrm{~h}$. ment (Table 2). Among the 3 methods, the HPLC and biosensor methods could complete one injection in less than 10 min, whereas the microbiological assay took 24 $\mathrm{h}$ for one cycle analysis. Moreover, the HPLC method exhibited better sensitivity and reproducibility.

\section{$\beta$-Lactamase Stability During Milk Pasteurization, Sterilization, and Storage}

Generally, in cases of economically motivated adulteration, $\beta$-lactamases are illegally added to raw milk contaminated with antibiotics after its collection from the dairy farm. It is important to investigate changes in $\beta$-lactamase activity that might occur during milk manufacture and sales. Raw milk may contain many pathogens. Therefore, pasteurization or sterilization is necessary to reduce or eliminate microorganisms that may cause diseases, and is generally performed by heating milk to a specific temperature for a certain time. Pasteurization could be a low-temperature, long-time (LTLT) process or a high-temperature, short-time 
(a)

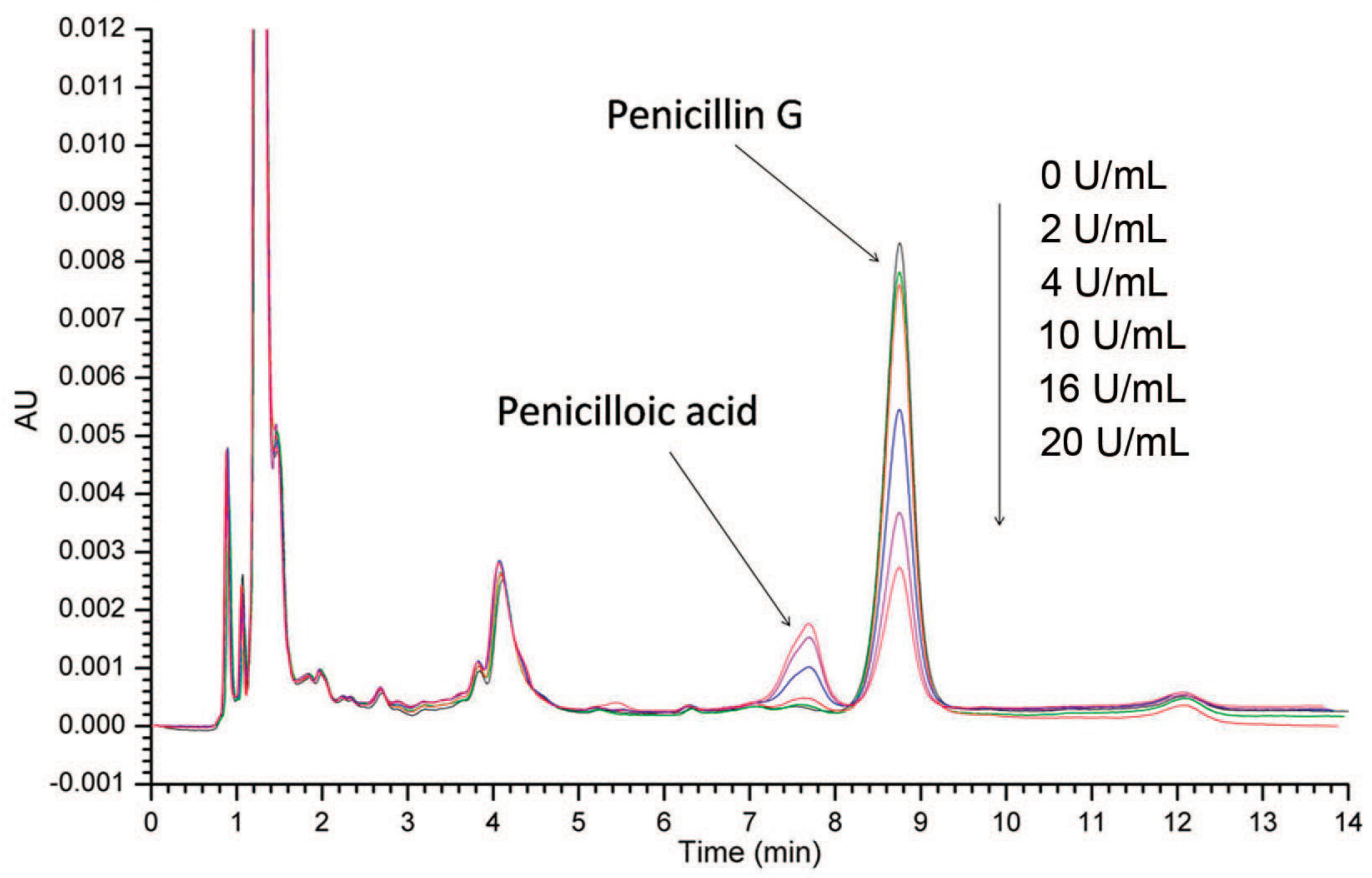

(b)

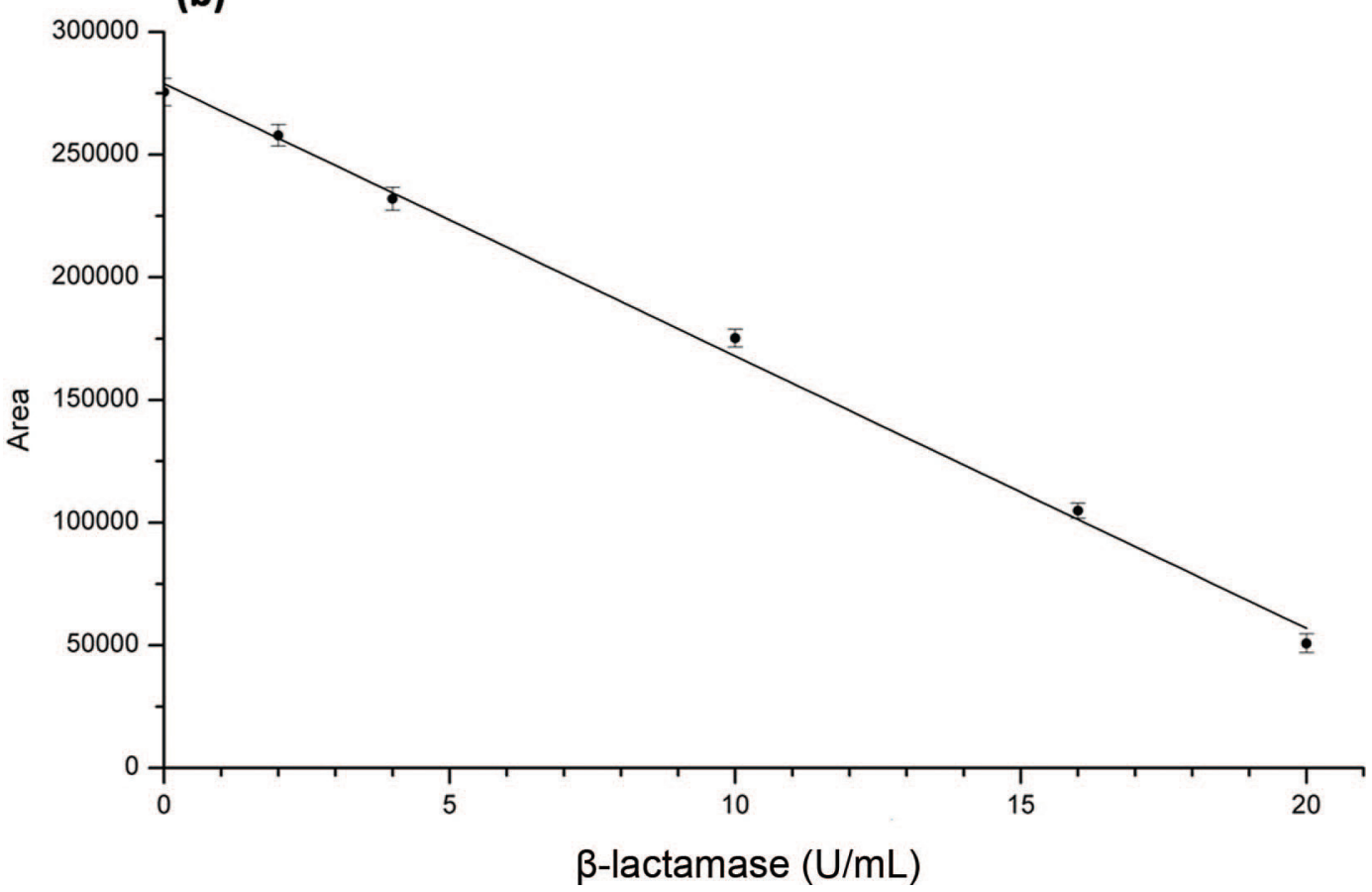

Figure 3. Matrix-matched $\beta$-lactamase calibration plot (b) and the corresponding overlapped chromatograms (a) recorded using the HPLCUV system. Color version available online.

(HTST) process. In this study, we investigated both LTLT $\left(65^{\circ} \mathrm{C}\right.$ for $\left.30 \mathrm{~min}\right)$ and $\operatorname{HTST}\left(80^{\circ} \mathrm{C}\right.$ for $\left.15 \mathrm{~s}\right)$ pasteurization as well as UHT sterilization (UHTS, $135^{\circ} \mathrm{C}$ for $10 \mathrm{~s}$ ). Fortified milk (containing $10 \mathrm{U} / \mathrm{mL}$ $\beta$-lactamase) was pasteurized or sterilized according to the above conditions before reaction with penicillin G. The variations of $\beta$-lactamase were determined by the developed HPLC-UV method (Figure 4). Pasteurization treatment (LTLT and HTST) of the milk before the penicillin $\mathrm{G}$ standard was added did not visibly in- 
Table 1. Recovery and precision studies for determination of $\beta$-lactamase in milk $(\mathrm{n}=6)$

\begin{tabular}{lccc}
\hline $\begin{array}{l}\beta \text {-lactamase } \\
\text { added }(\mathrm{U} / \mathrm{mL})\end{array}$ & $\begin{array}{c}\beta \text {-lactamase } \\
\text { measured }(\mathrm{U} / \mathrm{mL})\end{array}$ & $\begin{array}{c}\text { Recovery } \\
(\%)\end{array}$ & $\begin{array}{c}\mathrm{CV} \\
(\%)\end{array}$ \\
\hline 2.0 & 2.10 & 105 & 5.8 \\
6.0 & 5.65 & 94 & 4.3 \\
12.0 & 12.2 & 102 & 3.9 \\
18.0 & 17.6 & 98 & 2.2 \\
$50.0^{1}$ & 51.9 & 104 & 4.0 \\
\hline
\end{tabular}

${ }^{1}$ This sample was measured by the HPLC method after a 5-fold dilution.

fluence the activity of $\beta$-lactamase in the milk sample, whereas the $\beta$-lactamase activity was clearly decreased following UHTS treatment.

Similarly, the effect of short-time chilled storage $\left(4^{\circ} \mathrm{C}\right.$, 1 to $7 \mathrm{~d}$ ) on $\beta$-lactamase activity in milk was studied, and little effect was observed, as shown in Figure 5. The above results indicated that besides being a quality control strategy during milk collection, the HPLC-UV method could also be used to monitor $\beta$-lactamase in commercial pasteurization milk products.

\section{Determination of $\beta$-Lactamase in Milk Products}

Using the proposed HPLC method, 36 pasteurized milk products bought locally were analyzed, and 3 quality control samples (containing 2, 4, and 10 $\mathrm{U} / \mathrm{mL} \beta$-lactamase) were randomly inserted into the sample sequence to ensure test accuracy. Among the 36 samples, detectable $\beta$-lactamases were found in only 2 samples (approximately 1.2 and $2.6 \mathrm{U} / \mathrm{mL}$ ), close to the limit of quantification. The results correlated well with other monitoring reports carried out recently (Xu et al., 2010; Zhou et al., 2013). Because the pasteurization procedure did not visibly influence the activity of $\beta$-lactamase, the screening of pasteurized milk products could effectively eliminate the illegal practice in the local dairy industry. The detected low activity of $\beta$-lactamase was apparently insufficient for effective

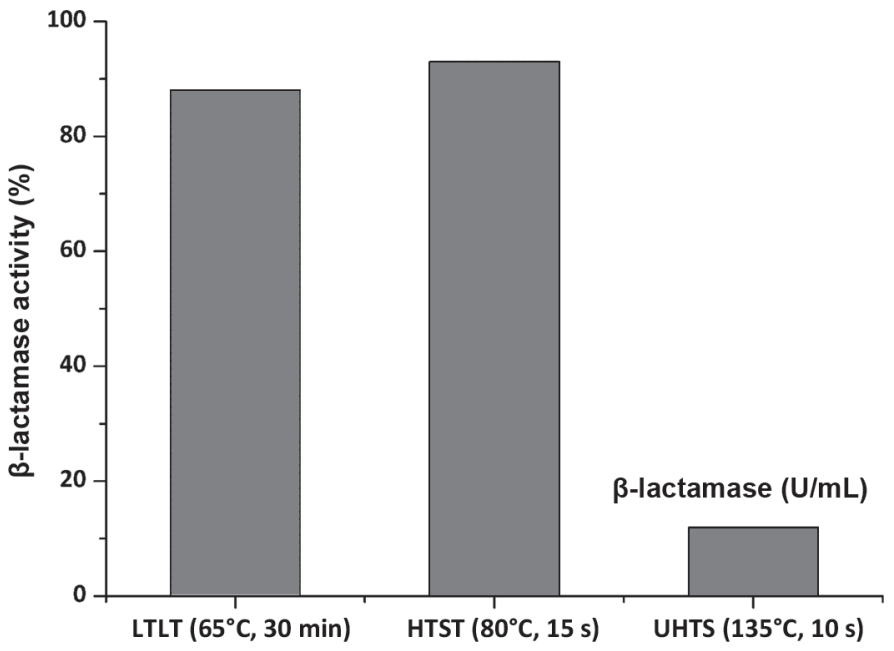

Figure 4. Effects of pasteurization and sterilization on $\beta$-lactamase activity in milk. LTLT = low-temperature, long-time pasteurization; HTST $=$ high-temperature, short-time pasteurization; UHTS = ultrahigh-temperature sterilization.

elimination of the antibiotic residues in contaminated milk, and thus was attributed to endogenous production in dairy cattle. It is widely reported that many pathogenic microbial strains can mutate to hyperproduce $\beta$-lactamases (Sanders and Sanders, 1992; Philippon et al., 2002; Paterson and Bonomo, 2005; Walsh et al., 2005); therefore, the animals infected by such pathogenic microorganisms may produce $\beta$-lactamases endogenously. Therefore, a technique capable of identifying endogenous and exogenous $\beta$-lactamase is highly desirable.

\section{CONCLUSIONS}

We developed and demonstrated a simple, rapid, sensitive, and robust method for indirect quantification of $\beta$-lactamase activity in milk using HPLC-UV. The novel method is a rapid strategy that can provide accurate quantitative results. Convenient operation

Table 2. Comparison of results from the HPLC method, thermometric biosensor, and microbiological assay (Micro) for determination of $\beta$-lactamase in milk $(\mathrm{n}=4)$

\begin{tabular}{|c|c|c|c|c|c|c|c|c|c|}
\hline \multirow{2}{*}{$\begin{array}{l}\beta \text {-lactamase } \\
\text { added } \\
(\mathrm{U} / \mathrm{mL})\end{array}$} & \multicolumn{3}{|c|}{$\beta$-lactamase measured $(\mathrm{U} / \mathrm{mL})$} & \multicolumn{3}{|c|}{ Recovery (\%) } & \multicolumn{3}{|c|}{$\mathrm{CV}(\%)$} \\
\hline & HPLC & Biosensor & Micro & HPLC & Biosensor & Micro & HPLC & Biosensor & Micro \\
\hline 0 & $\mathrm{ND}^{1}$ & ND & ND & - & - & - & - & - & - \\
\hline 4.0 & 3.89 & 4.3 & Positive & 97 & 108 & - & 5.6 & 7.2 & - \\
\hline 10.0 & 10.4 & 9.7 & Positive & 104 & 97 & - & 4.1 & 5.0 & - \\
\hline 20.0 & 19.3 & 19.0 & Positive & 96 & 95 & - & 2.7 & 3.5 & - \\
\hline $40.0^{2}$ & 41.7 & 42.6 & $>20$ & 104 & 106 & - & 4.6 & 5.8 & - \\
\hline
\end{tabular}




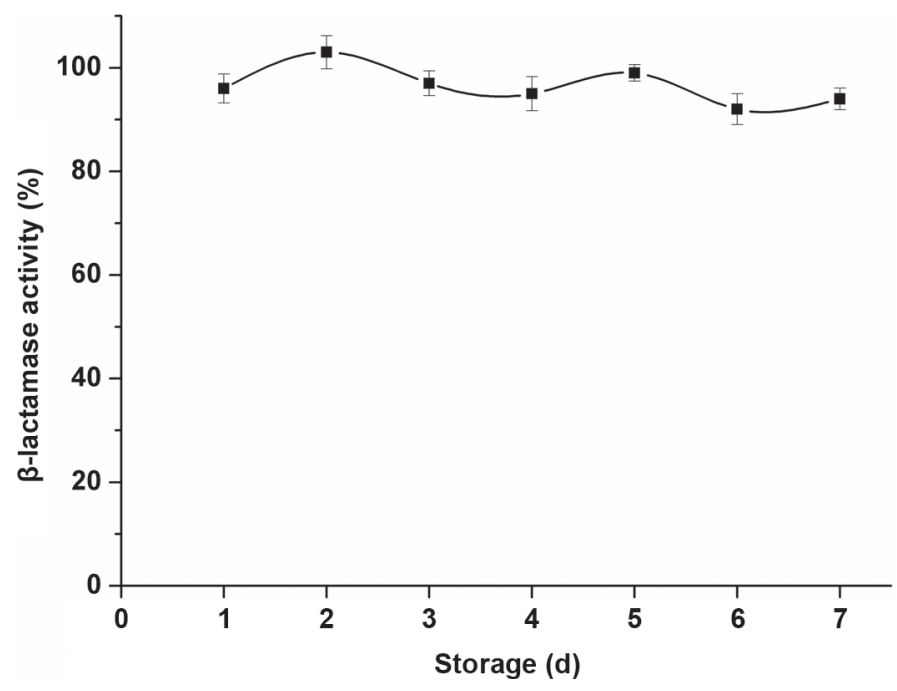

Figure 5. Effect of short-time chilling storage $\left(4^{\circ} \mathrm{C}\right)$ on $\beta$-lactamase activity in milk.

for sample pretreatment speeds up and simplifies the assay protocol. After optimization and validation, the method achieved satisfactory sensitivity and good precision. We successfully applied the method to screening commercial milk products and monitoring activity of $\beta$-lactamase during milk storage and sterilization, and the results correlated well with results from 2 reference methods established previously. The easily accessibility of the HPLC-UV instrument makes this method a valuable tool for daily use in quality control.

\section{ACKNOWLEDGMENTS}

This work was supported by National Natural Science Foundation of China (Beijing, China; grant nos. 31471671, 81001248, and 21445009).

\section{REFERENCES}

Abraham, E. P., and E. Chain. 1940. An enzyme from bacteria able to destroy penicillin. Nature 146:837.

Ashwin, H. M., S. L. Stead, J. C. Taylor, J. R. Startin, S. F. Richmond, V. Homer, T. Bigwood, and M. Sharman. 2005. Development and validation of screening and confirmatory methods for the detection of chloramphenicol and chloramphenicol glucuronide using SPR biosensor and liquid chromatography-tandem mass spectrometry. Anal. Chim. Acta 529:103-108.

Bush, K., and G. A. Jacoby. 2010. Updated functional classification of beta-lactamases. Antimicrob. Agents Chemother. 54:969-976.

Cui, S. H., J. Y. Li, C. Q. Hu, S. H. Jin, and Y. Ma. 2007. Development of a method for the detection of beta-lactamases in milk samples. J. AOAC Int. 90:1128-1132.

Gao, W. Z., B. G. Xing, R. Y. Tsien, and J. H. Rao. 2003. Novel fluorogenic substrates for imaging $\beta$-lactamase gene expression. J. Am. Chem. Soc. 125:11146-11147.

Goyal, A., A. Prasad, U. Ghoshal, and K. N. Prasad. 2008. Comparison of disk diffusion, disk potentiation \& double disk synergy methods for detection of extended spectrum beta lactamases in Enterobacteriaceae. Indian J. Med. Res. 128:209-211.

Hujer, A. M., K. S. Keslar, N. J. Dietenberger, C. R. Bethel, A. Endimiani, and R. A. Bonomo. 2009. Detection of SHV beta-lactamases in Gram-negative bacilli using fluorescein-labeled antibodies. BMC Microbiol. 9:46.

Hujer, A. M., M. G. P. Page, M. S. Helfand, B. Yeiser, and R. A. Bonomo. 2002. Development of a sensitive and specific enzymelinked immunosorbent assay for detecting and quantifying CMY-2 and SHV $\beta$-lactamases. J. Clin. Microbiol. 40:1947-1957.

Ikryannikova, L. N., E. A. Shitikov, D. G. Zhivankova, E. N. Il'ina, M. V. Edelstein, and V. M. Govorun. 2008. A MALDI TOF MSbased minisequencing method for rapid detection of TEM-type extended-spectrum beta-lactamases in clinical strains of Enterobacteriaceae. J. Microbiol. Methods 75:385-391.

Jorgensen, J. H., S. A. Crawford, and G. A. Alexander. 1982. Pyridinium-2-azo- $p$-dimethylaniline chromophore, a new chromogenic cephalosporin for rapid beta-lactamase testing. Antimicrob. Agents Chemother. 22:162-164.

Kantiani, L., M. Farr, and D. Barcel. 2009. Analytical methodologies for the detection of $\beta$-lactam antibiotics in milk and feed samples. Trends Analyt. Chem. 28:729-744.

Korycka-Dahl, M., T. Richardson, and R. L. Bradley. 1985. Use of microbial beta-lactamase to destroy penicillin added to milk. J. Dairy Sci. 68:1910-1916.

Liang, P., R. I. Sanchez, and M. T. Martin. 1996. Electrochemiluminescence-based detection of $\beta$-lactam antibiotics and $\beta$-lactamases. Anal. Chem. 68:2426-2431.

Liu, R. R., R. S. Liew, J. Zhou, and B. G. Xing. 2007. A simple and specific assay for real-time colorimetric visualization of $\beta$-lactamase activity by using gold nanoparticles. Angew. Chem. Int. Ed. Engl. 46:8799-8803.

Livermore, D. M., and M. Yuan. 1996. Antibiotic resistance and production of extended-spectrum beta-lactamases amongst Klebsiella spp. from intensive care units in Europe. J. Antimicrob. Chemother. 38:409-424.

López-Cerero, L., P. Egea, L. Serrano, D. Navarro, A. Mora, J. Blanco, Y. Doi, D. L. Paterson, J. Rodriguez-Bano, and A. Pascual. 2011. Characterisation of clinical and food animal Escherichia coli isolates producing CTX-M-15 extended-spectrum beta-lactamase belonging to ST410 phylogroup A. Int. J. Antimicrob. Agents $37: 365-367$.

O'Callaghan, C. H., A. Morris, S. M. Kirby, and A. H. Shingler. 1972. Novel method for detection of $\beta$-lactamases by using a chromogenic cephalosporin substrate. Antimicrob. Agents Chemother. $1: 283-288$

Paterson, D. L., and R. A. Bonomo. 2005. Extended-spectrum $\beta$-lactamases: A clinical update. Clin. Microbiol. Rev. 18:657-686.

Paterson, D. L., L. B. Rice, and R. A. Bonomo. 2001. A rapid method of extraction and analysis of extended spectrum $\beta$-lactamases from clinical strains of Klebsiella pneumoniae. Clin. Microbiol. Infect. 7:709-711.

Pengov, A., and A. Kirbis. 2009. Risks of antibiotic residues in milk following intramammary and intramuscular treatments in dairy sheep. Anal. Chim. Acta 637:13-17.

Perret, C. J. 1954. Iodometric assay of penicillinase. Nature 174:10121013.

Philippon, A., G. Arlet, and G. A. Jacoby. 2002. Plasmid-determined AmpC-type beta-lactamases. Antimicrob. Agents Chemother. 46:1-11.

Rubtsova, M. Y., M. M. Ulyashova, M. V. Edelstein, and A. M. Egorov. 2010. Oligonucleotide microarrays with horseradish peroxidase-based detection for the identification of extended-spectrum $\beta$-lactamases . Biosens. Bioelectron. 26:1252-1260.

Sanders, C. C., and W. E. Sanders Jr.. 1992. Beta-lactam resistance in gram-negative bacteria: Global trends and clinical impact. Clin. Infect. Dis. 15:824-839.

Stead, S. L., H. Ashwin, S. F. Richmond, M. Sharman, P. C. Langeveld, J. P. Barendse, J. Stark, and B. J. Keely. 2008. Evaluation and validation according to international standards of the Del- 
votest (R) SP-NT screening assay for antimicrobial drugs in milk. Int. Dairy J. 18:3-11.

Voets, G. M., A. C. Fluit, J. Scharringa, J. C. Stuart, and M. A. Leverstein-van Hall. 2011. A set of multiplex PCRs for genotypic detection of extended-spectrum beta-lactamases, carbapenemases, plasmid-mediated AmpC beta-lactamases and OXA beta-lactamases. Int. J. Antimicrob. Agents 37:356-359.

Walsh, T. R., M. A. Toleman, L. Poirel, and P. Nordmann. 2005. Metallo- $\beta$-lactamases: The quiet before the storm? Clin. Microbiol. Rev. 18:306-325.

Xing, B., A. Khanamiryan, and J. H. Rao. 2005. Imaging gene expression with a cell-permeable near infrared $\beta$-lactamase substrates. J. Am. Chem. Soc. 127:4158-4159.
Xu, Z., H. Y. Wang, S. X. Huang, Y. L. Wei, S. J. Yao, and Y. L. Guo. 2010. Determination of $\beta$-lactamase residues in milk using matrix-assisted laser desorption/ionization Fourier transform mass spectrometry. Anal. Chem. 82:2113-2118.

Yang, Z., P. L. Ho, G. Liang, K. H. Chow, Q. Wang, Y. Cao, Z. Guo, and $\mathrm{B}$. Xu. 2007. Using beta-lactamase to trigger supramolecular hydrogelation. J. Am. Chem. Soc. 129:266-267.

Yang, Z., G. Liang, and B. Xu. 2008. Enzymatic hydrogelation of small molecules: A new way to generate biomaterials. Acc. Chem. Res. 41:315-326.

Zhou, S., Y. F. Zhao, M. Mecklenburg, D. J. Yang, and B. Xie. 2013. A novel thermometric biosensor for fast surveillance of $\beta$-lactamase activity in milk. Biosens. Bioelectron. 49:99-104. 